\title{
Topônimos diamantinos: motivação, estrutura morfológica e etimologia
}

\author{
Topónimos diamantinos: motivación, estructura morfológica y etimología
}

Diamantine toponyms: motivation, morphological structure and etimology

\author{
Elias de Souza Santos ${ }^{1}$ \\ Edgar Souza da Silva
}

\begin{abstract}
Resumo
Neste trabalho apresentamos um estudo toponímico, afim de verificar tendências no processo de nomeação das microrregiões que compõem o território de identidade denominado Chapada Diamantina/BA. Os topônimos foram inventariados a partir de mapas digitalizados, disponibilizados pelo IBGE (2010), e analisados à luz dos pressupostos teórico-metodológicos propostos por Dick $(1980,1990,1992)$ para organização das informações acerca desses topônimos, discussão dos aspectos motivacionais, estrutura morfológica e etimologia. Verificamos com a análise que os aspectos motivacionais que se apresentaram de maneira substancial foram os de natureza física, em especial, àqueles correspondentes à flora, fauna e hidrografia e, quanto à forma dos signos toponímicos, foram mais evidentes aqueles de categoria simples e, no que se refere a etimologia, destacaram-se os étimos de línguas indígenas. Assim, constatamos que as informações acerca dos topos vão além do léxico e instituem um conjunto de saberes sócio-histórico-culturais.
\end{abstract}

Palavras-chave: Lexicologia; Topônimos; Taxionomia; Chapada Diamantina/BA.

\section{Resumen}

En este trabajo presentamos un estudio toponímico, a fin de verificar tendencias en el proceso de nominación de las microrregiones que componen el territorio de identidad denominado Chapada Diamantina/BA. Los topónimos fueron inventariados a partir de mapas digitalizados, disponibles por el IBGE (2010), y analizados a la luz de los presupuestos teórico-metodológicos propuestos por Dick $(1980,1990,1992)$ para la organización de las informaciones sobre estos topónimos, discusión de los aspectos motivacionales, estructura morfológica y etimología. Verificamos en el análisis que los aspectos motivacionales que se presentaron de manera sustancial fueron los de naturaleza física, en especial, a aquellos correspondientes a la flora, fauna e hidrografía y, en cuanto a la forma de los signos toponímicos, fueron más evidentes aquellos de categoría simple y, en lo que se refiere a etimología, se destacaron los étimos de las lenguas indígenas. Así, constatamos que las informaciones sobre los topes van más allá del léxico e instituyen un conjunto de saberes sociohistorico-culturales.

Palabras clave: Lexicología; Topónimos; Taxonomía; Chapada Diamantina/BA.

\begin{abstract}
In this paper we present a toponymic study, in order to verify trends in the process of naming the micro regions that constitutes the identity territory called Chapada Diamantina/BA. The toponyms were inventoried from digitized maps, made available by IBGE (2010), and analyzed in the light of the theoretical and methodological assumptions proposed by Dick $(1980,1990,1992)$ to organize information about these toponyms, discussion of motivational aspects, structure morphology and etymology. After the analysis, we verified that the motivational aspects that were presented in a substantial way were those of physical nature, in particular, those corresponding
\end{abstract}

\footnotetext{
${ }^{1}$ Mestre e doutorando em Estudos Linguísticos pela Universidade Estadual de Feira de Santana. Professor Substituto de Língua Portuguesa/Linguística na Universidade do Estado da Bahia (UNEB) - Campus XXII, Seabra/BA, Brasil. elias40_d@hotmail.com.

${ }^{2}$ Graduando do curso de Letras - Língua Portuguesa e Literaturas pela Universidade do Estado da Bahia (UNEB) - Campus XXII, Seabra/BA, Brasil. silvaedgar123edgar@gmail.com.
} 
to the flora, fauna and hydrography. As for the form of the toponymic signs, those of simple category were more evident. In regard to the etymology, those corresponding to the indigenous languages were highlighted. Thus, we find that the information about the topos goes beyond the lexicon and establishes a set of socio-historicalcultural.

Keywords: Lexicology; Toponyms; Taxionomy; Chapada Diamantina/BA.

\section{Primeiros dizeres}

O topônimo é uma expressão usada para designar um lugar, isto é, um acidente geográfico, físico ou humano. Ele é objeto de estudo da toponímia, ciência lexicológica responsável por distinguir, identificar e nomear os acidentes de determinados espaços geográficos, históricos, sociais e culturais.

Mas, afinal, o que é toponímia? Encontramos na enciclopédia luso-brasileira que a toponímia é uma palavra de origem grega, formada do étimos topos que significa "lugar" e onoma "nome", ou seja, estudo dos nomes de lugares. Segundo Salazar-Quijada (1985, p. 18), toponímia é a “[...] rama de la Onomástica que se ocupa del estúdio integral, en el espacio y en tiempo, de los aspectos: geo-históricos, socioeconómicos e antropo-linguísticos, que permitiron y permiten que um nombre de lugar se origine y subsista ${ }^{3}$ ".

Para a produção deste artigo, escolhemos como corpus de estudo mapas da Chapada Diamantina, digitalizados e disponibilizados pelo IBGE (2010), a fim de realizar uma análise toponímica. De tal modo, analisamos os topônimos encontrados nos mapas e, dessa maneira, estudamo-los sob a ótica das taxionomias que lhes referem, tendo com isso, um estudo voltado ao léxico, principalmente para a onomástica ou onomatologia ${ }^{4}$ - ciência dos nomes próprios - cujo outro ramo, se ocupa do estudo dos nomes próprios de pessoas, a antroponímia (MAEDA, 2006, p. 34).

Diante das premissas expostas nos parágrafos anteriores, o estudo que aqui delineamos se voltou aos topos, sua localização, categorização e identificação, permitindo uma apreensão mais adequada de um conjunto de saberes sócio-histórico-culturais sobre o lugar.

\section{Aspectos teórico-metodológicos}

\footnotetext{
${ }^{3}$ É o ramo da onomástica que se ocupa do estudo integral, no espaço e no tempo, dos aspectos: geo-históricos, sócio-econômicos e antropo-linguísticos, que permitiram e permitem que o nome de um lugar origine e subsista.

${ }^{4}$ José Leite Vasconcelos (1931), chama de Onomatologia o ramo da Glotologia que estuda os nomes próprios, e subdivide-a por três partes: a Antroponímia, Toponímia e Vários nomes próprio.
} 
Os nomes de lugares, em geral, são investigados a partir de três planos: o motivacional, o estrutural e o linguístico, sendo que este segundo correspondente à sua morfologia e aquele terceiro à sua etimologia.

Para o plano motivacional, elegemos o modelo taxionômico de Dick (1992, p. 31-34). Esse modelo, divide os nomes em duas grandes categorias (os de natureza física e os de natureza antropocultural) de acordo com a ideia/elemento que teria motivado o denominador no momento de nomeação. Vejamos a distribuição taxionômica no quadro a seguir:

\begin{tabular}{|c|l|l|}
\hline \multicolumn{2}{|c|}{ TAXIONOMIAS DE NATUREZA FÍSICA } \\
\hline $\mathrm{N}^{\circ}$. & \multicolumn{1}{|c|}{ CATEGORIAS } & \multicolumn{1}{c|}{ ELEMENTOS MOTIVADORES } \\
\hline 01 & Astrotopônimos & Topônimos referentes aos corpos celestes \\
\hline 02 & Cardinotopônimos & Topônimos referentes às posições geográficas \\
\hline 03 & Cromotopônimos & Topônimos referentes às cores, escala cromática \\
\hline 04 & Dimensiotopônimos & Topônimos referentes às dimensões - extensão, largura, altura, profundidade \\
\hline 05 & Fitotopônimos & Vegetação \\
\hline 06 & Geomorfotopônimos & Topônimos referentes às formas topográficas \\
\hline 07 & Hidrotopônimos & Topônimos referentes à hidrografia \\
\hline 08 & Litotopônimos & $\begin{array}{l}\text { Topônimos referentes aos itens de índole mineral e aspectos relativos à constituição do } \\
\text { solo }\end{array}$ \\
\hline 09 & Meteorotopônimos & Topônimos referentes aos fenômenos atmosféricos \\
\hline 10 & Morfotopônimos & Topônimos referentes às formas genéricas \\
\hline 11 & Zootopônimos & Topônimos referentes aos animais \\
\hline & \multicolumn{2}{|c|}{$\begin{array}{l}\text { Fuadro 01: Taxionomias toponímicas quanto à motivação } \\
\end{array}$} \\
\end{tabular}

\begin{tabular}{|c|l|l|}
\hline \multicolumn{3}{|c|}{ TAXIONOMIAS DE NATUREZA ANTROPOCULTURAL } \\
\hline $\mathrm{N}^{\circ}$. & \multicolumn{1}{|c|}{ CATEGORIAS } & \multicolumn{1}{c|}{ ELEMENTOS MOTIVADORES } \\
\hline 01 & Animotopônimos & Topônimos referentes a vida psíquica, cultural espiritual \\
\hline 02 & Antropotopônimos & Topônimos referentes aos nomes próprios individuais \\
\hline 03 & Axiotopônimos & $\begin{array}{l}\text { Topônimos referente aos títulos e dignidades de que se fazem acompanhar os nomes } \\
\text { próprios individuais }\end{array}$ \\
\hline 04 & Corotopônimos & Topônimos referentes aos nomes de cidades, países, estados, regiões e continentes \\
\hline 05 & Cronotopônimos & Topônimos que encerram indicadores cronológicos \\
\hline 06 & Ecotopônimos & Topônimos referentes as habitações de um modo geral \\
\hline 07 & Ergotopônimos & Topônimos referentes a elementos da cultura material \\
\hline 08 & Etnotopônimos & Topónimos referentes aos elementos étnicos, isolados ou não (povos, tribos, castas) \\
\hline 09 & Dirrematotopônimos & Topônimos construídos por frases ou enunciados \\
\hline 10 & Hierotopônimos & Topônimos relativos aos nomes sagrados de diferentes crenças \\
\hline 11 & Historiotopônimos & $\begin{array}{l}\text { Topônimos referentes aos movimentos de cunho histórico-social e aos seus membros, } \\
\text { assim como as datas correspondentes }\end{array}$ \\
\hline 12 & Hodotopônimos & Topônimos correspondentes às vias de comunicação rural ou urbana \\
\hline 13 & Numerotopônimos & Topônimos relativos aos adjetivos numerais \\
\hline 14 & Poliotopônimos & Topônimos constituídos pelos vocábulos vila, aldeia, cidade, povoação, arraial \\
\hline 15 & Sociotopônimos & $\begin{array}{l}\text { Topônimos referentes as atividades profissionais, aos locais de trabalho e aos pontos } \\
\text { de encontro dos membros de uma comunidade (largo, pátio, praça). }\end{array}$ \\
\hline 16 & Somatopônimos & $\begin{array}{l}\text { Topônimos empregados em relação metafórica as partes do corpo humano ou do } \\
\text { animal. }\end{array}$ \\
\hline
\end{tabular}

Quadro 02: Taxionomias toponímicas quanto à motivação

Fonte: Elaborado pelos autores, baseado em Dick (1992, p. 31-34) 
No que diz respeito à estrutura dos acidentes geográficos, Dick (1992, p. 10) diz que “[...] o topônimo, em sua formação na nomenclatura onomástica, liga-se ao acidente geográfico que o identifica, com ele constituindo um conjunto ou uma relação binômica, que se pode seccionar para melhor se distinguirem seus termos formadores”. É dessa relação binômica que extraímos o elemento ou termo genérico (relativo ao que é comum no conjunto) e o elemento ou termo específico (que particulariza sua entidade geográfica).

Em tal caso, é tido como simples o topônimo, cujo elemento ou termo específico for constituído de apenas um formante e composto aquele constituído por mais de um formante. Além do que, tanto os topônimos simples quanto os compostos, em sua estrutura, podem apresentar elementos da mesma língua (denominados simples híbridos) ou de línguas distintas (denominados de compostos híbridos).

Além da motivação e estrutura, a língua de origem do topos costuma ser foco de investigação, centrando-se em consultas de obras lexicográficas, especialmente as de cunho etimológico. Para este estudo, consultamos, conforme as especificidades de cada nome, algumas obras de referência, a saber: Dicionário on line Caudas Aulete, Dicionário histórico das palavras portuguesas de origem tupi (CUNHA, 1998) e Dicionário etimológico da língua portuguesa (CUNHA, 1986).

Em concordância com o que já foi exposto na introdução deste estudo, os dados foram coletados de mapas digitais do território de identidade Chapada Diamantina, na escala de 1: 100.000, disponibilizados pelo IBGE (2010). Ao todo, foram coletados 23 nomes de microrregiões, em sua totalidade, todas as que constituem o território, formando assim o corpus da investigação.

Com efeito, antes da apresentação da análise, julgamos importante sumarizar sobre os aspectos sociodemográficos e histórico-culturais da Chapada Diamantina/BA, elementos relevantes que porventura contribuíram para o processo de nomeação dos topos em estudo.

\section{Chapada diamantina: das minas aos seus encantos}

O povoamento da Chapada Diamantina está intrinsecamente ligado ao ciclo do diamante e do ouro. Suas minas seduziram muitos exploradores, em sua grande maioria, mineiros e paulistas, que percorriam as terras do sertão em busca de riquezas, numa verdadeira corrida rumo à fortuna. Isto posto, houve uma intensa migração de homens para tirar proveito dos fins lucrativos com a venda de diamantes no interior da Bahia. 
Quando uma coligação de garimpeiros encontrava uma jazida, edificavam em pouco tempo arraiais que se expandiam formando vilas e, que, depois, se constituíam em cidades. Nestas cidades, passaram a imperar a disputa de poderes entre oligarquias representadas por coronéis. "O analfabetismo reinante, as precárias condições de vida, o desemprego, a falta de assistência são alguns fatores que, naquela época, fizeram do sertanejo um prisioneiro do coronel que quase sempre os acolhia em troca de "gratidão"' (ROLO, 2010, p. 94-95). Esses coronéis tornavam estes homens jagunços para lutar a seu favor em caso de ameaças, sem contar o que reitera (PIRES, 1999 apud CRUZ, 2006, p. 18) que, nesse processo de povoamento, houve uma "dizimação de grupos indígenas ali existentes", exploração do "trabalho escravo com negros já livres", intensificação da "[...] presença de bandeirantes e exploradores de garimpos de ouro e diamante, varrendo o sertão com diferentes práticas de violência”.

A chapada foi palco de intensas lutas e conflitos pela busca incessante de poder. No século XX, sofreu com a instabilidade promovida pela passagem da coluna prestes, denominada pelos sertanejos de "revoltosos". É anterior a esse cenário e, no mesmo, que as microrregiões que hoje compõe o território se desabrocharam.

O Território Chapada Diamantina, localizado no centro do estado da Bahia, constituise de 23 microrregiões, são elas: Abaíra, Andaraí, Barra da Estiva, Boninal, Bonito, Ibicoara, Ibitiara, Iraquara, Itaeté, Jussiape, Lençóis, Marcionílio Souza, Morro do Chapéu, Mucugê, Nova Redenção, Novo Horizonte, Palmeiras, Piatã, Rio de Contas, Seabra, Souto Soares,

Utinga e Wagner, com uma área total de $30.458,88 \mathrm{Km}^{2}$ (SEI, 2010).

Listadas as microrregiões que compõem o território já supracitado, exibimos na seção a seguir uma breve análise toponímica considerando os aspectos motivacionais, morfoestruturais e etimológicos.

\subsection{Do plano motivacional}

Visualizemos no quadro a seguir os topônimos inventariados e distribuídos por taxionomias: 
RELACult - Revista Latino-Americana de Estudos em Cultura e Sociedade

\begin{tabular}{|c|c|c|}
\hline & TOPÔNIMO & TAXIONOMIA \\
\hline 1. & Abaíra & Zootopônimo \\
\hline 2. & Andaraí & Zootopônimo \\
\hline 3. & Barra da Estiva & Hidrotopônimo \\
\hline 4. & Boninal & Fitotopônimo \\
\hline 5. & Bonito & Animotopônimo \\
\hline 6. & Ibicoara & Litotopônimo \\
\hline 7. & Ibitiara & Geomorfotopônimo \\
\hline 8. & Iraquara & Zootopônimo \\
\hline 9. & Itaité & Litotopônimo \\
\hline 10. & Jussiape & Cardinotopônimo \\
\hline 11. & Lençóis & Ergotopônimo \\
\hline 12. & Marcionílio Souza & Antropotopônimo \\
\hline 13. & Morro do Chapéu & Geomorfotopônimo \\
\hline 14. & Mucugê & Fitotopônimo \\
\hline 15. & Nova redenção & Animotopônimo \\
\hline 16. & Novo Horizonte & Animotopônimo \\
\hline 17. & Palmeiras & Fitotopônimo \\
\hline 18. & Piatã & Animotopônimo \\
\hline 19. & Rio de contas & Hidrotopônimo \\
\hline 20. & Seabra & Antrotopônimo \\
\hline 21. & Souto Soares & Antropotopônimo \\
\hline 22. & Utinga & Hidrotopônimo \\
\hline 23. & Wagner & Antropotopônimo \\
\hline
\end{tabular}

Com a distribuição taxionômica dos topônimos observados no quadro 3, selecionamos 4 topônimos e apresentamo-los, em fichas toponímicas, conforme a metodologia de Dick (1980 [1990]). Para tal, mencionamos o referente topônimo, sua taxionomia, o acidente, a localização geográfica, a etimologia, o percurso onomástico e as respectivas informações enciclopédicas. 
RELACult - Revista Latino-Americana de Estudos em Cultura e Sociedade

Revista Latinoamericana de Estudios en Cultura y Sociedad | Latin American Journal of Studies in Culture and Society V. 05, no 01, jan-abr., 2019, artigo n ${ }^{\circ} 1423$ | claec.org/relacult | e-ISSN: 2525-7870

\begin{tabular}{|c|c|}
\hline TOPÔNIMO & TAXIONOMIA \\
\hline ACIDENTE & Humano/município \\
\hline $\begin{array}{c}\text { LOCALIZAÇÃO } \\
\text { GEOGRÁFICA }\end{array}$ & $\mathrm{TI}^{5} 03$ \\
\hline ETIMOLOGIA & Indígena. ANDYRÁ-Y, em tup. ant., 'rio dos morcegos' (NAVARRO, 2013). \\
\hline $\begin{array}{c}\text { PERCURSO } \\
\text { ONOMÁSTICO }\end{array}$ & $\begin{array}{l}\text { Andaraí } \\
\text { Zootopônimo }\end{array}$ \\
\hline $\begin{array}{c}\text { INFORMAÇÕES } \\
\text { ENCICLOPẼDICAS }\end{array}$ & $\begin{array}{l}\text { O território do município foi primitivamente habitado ou visitado pelos índios } \\
\text { cariris. A penetração inicial ocorreu por volta de } 1845 \text { e visava à busca de } \\
\text { minas de ouro e diamante. Criou-se então a povoação de Andaraí, que foi } \\
\text { crescendo com a vinda de indivíduos de outras classes, a criação do comércio } \\
\text { local e a construção da capela. Presume-se que a designação Andaraí tenha sido } \\
\text { inspirada pela abundância de água e pela presença de morcegos nas grandes } \\
\text { lapas existentes na região. A Lei provincial n. } 1.811 \text {, de } 11-06-1878 \text {, criou o } \\
\text { distrito de paz de Andaraí e o elevou a sede de paróquia. A povoação foi } \\
\text { elevada à categoria de vila, pela Resolução provincial n. } 2.444 \text {, de } 19 \text { de maio } \\
\text { do mesmo ano, e o território elevou-se a município do mesmo nome. Não } \\
\text { havendo sido conseguida a canonização da freguesia, criada anteriormente em } \\
\text { 18-05-1888, a Lei imperial n. } 2.584 \text { a ratificou sob a invocação de Nossa } \\
\text { Senhora da Glória. O Ato de } 28-04-1891 \text { concedeu foros de cidade à sede do } \\
\text { município (IBGE, } 1958 \text {, v. XX). }\end{array}$ \\
\hline
\end{tabular}

Quadro 4: Ficha toponímica 1

Fonte: Elaborado pelos autores

\begin{tabular}{|c|c|}
\hline TOPÔNIMO & Geomorfotopônimo \\
\hline ACIDENTE & Humano/município \\
\hline $\begin{array}{l}\text { LOCALIZAÇÃO } \\
\text { GEOGRÁFICA }\end{array}$ & TI 03 \\
\hline ETIMOLOGIA & $\begin{array}{l}\text { Indígena. YBYTYRA-ARA, em tup. ant., 'cimo do morro, pico, cume' } \\
\text { (GREGÓRIO, 1980). }\end{array}$ \\
\hline $\begin{array}{c}\text { PERCURSO } \\
\text { ONOMÁSTICO }\end{array}$ & $\begin{array}{l}\text { Ibitiara < Bom Sucesso < Remédios do Rio de Contas < Remédios } \\
\text { Geomorfotopônimo<hierotopônimo<animotopônimo<animotopônimo. }\end{array}$ \\
\hline $\begin{array}{l}\text { INFORMAÇÕES } \\
\text { ENCICLOPÉDICAS }\end{array}$ & $\begin{array}{l}\text { A história do município teve início em fins do século XVIII, justamente } \\
\text { quando os desbravadores portugueses aqui chegaram em busca de ouro e } \\
\text { pedras preciosas. Inicialmente eles se fixaram num pequeno povoado que } \\
\text { atribuíram o nome de Remédios, por acreditarem que a água que ali jorrava da } \\
\text { serra com abundância teria qualidades terapêuticas o que constituía um } \\
\text { verdadeiro tesouro para os bandeirantes sedentos e cansados das longas } \\
\text { viagens. Posteriormente, esse povoado de Remédios foi elevado à categoria } \\
\text { de município sob a denominação de Remédios de Rio de Contas. Dentre os } \\
\text { arraiais pertencentes ao município de Remédios houvera um que mais se } \\
\text { destacou, e que posteriormente, recebera a denominação de Bom Sucesso, } \\
\text { uma invocação a Nossa Senhora do Bom Sucesso, e devido à descoberta de } \\
\text { jazidas de ouro na região, mudou-se para ali a sede do município. Em 1943, } \\
\text { através do Decreto n. 141, de } 31-12-1943 \text {, a denominação de Bom Sucesso foi } \\
\text { modificada para Ibitiara (IBGE, 1958, v. XX). } \\
\text { NOTA: O culto a Nossa Senhora do Bom Sucesso, protetora dos bens } \\
\text { terrenos, é comum na zona de mineração (CARVALHO, 2014). }\end{array}$ \\
\hline
\end{tabular}

Quadro 5: Ficha toponímica 2

Fonte: Elaborado pelos autores

\footnotetext{
${ }^{5}$ Território de identidade 03
} 
RELACult - Revista Latino-Americana de Estudos em Cultura e Sociedade

Revista Latinoamericana de Estudios en Cultura y Sociedad | Latin American Journal of Studies in Culture and Society V. 05, n⿳0 01, jan-abr., 2019, artigo no 1423 | claec.org/relacult |e-ISSN: 2525-7870

\begin{tabular}{|c|c|c|c|}
\hline TOPÔNIMO & Palmeiras & TAXIONOMIA & Fitotopônimo \\
\hline ACIDENTE & \multicolumn{3}{|c|}{ Humano/município } \\
\hline $\begin{array}{l}\text { LOCALIZAÇÃO } \\
\text { GEOGRÁFICA }\end{array}$ & \multicolumn{3}{|l|}{ TI 03} \\
\hline ETIMOLOGIA & \multicolumn{3}{|c|}{$\begin{array}{l}\text { Portuguesa. Pl. de Palmeira, forma der., do lat. palma -ae, 'nome comum a todas } \\
\text { as palmáceas' (CUNHA, 2013). }\end{array}$} \\
\hline $\begin{array}{c}\text { PERCURSO } \\
\text { ONOMÁSTICO }\end{array}$ & \multicolumn{3}{|c|}{$\begin{array}{l}\text { Palmeiras < Vila Bela das Palmeiras < Palmeiras } \\
\text { Fitotopônimo<poliotopônimo<fitotopônimo }\end{array}$} \\
\hline $\begin{array}{l}\text { INFORMAÇÕES } \\
\text { ENCICLOPÉDICAS }\end{array}$ & \multicolumn{3}{|c|}{$\begin{array}{l}\text { O povoamento do território iniciou-se a partir de } 1815 \text {, quando a descoberta de } \\
\text { diamantes no riacho Lajedinho, provocou o êxodo de garimpeiros para o local, } \\
\text { iniciando a formação do povoado Palmeiras. A Lei n. } 2.651 \text {, de } 14-05-1889 \text {, } \\
\text { elevou a povoação das Palmeiras a distrito de paz, subordinado ao município de } \\
\text { Lençóis. } \\
\text { Por Ato do Governador do Estado, de } 23-12-1890 \text {, foi a povoação elevada à } \\
\text { categoria de vila com a denominação de Vila Bela das } \\
\text { Palmeiras e criado o município do mesmo nome, com território desmembrado de } \\
\text { Lençóis. No ano de } 1930 \text {, por força do Decreto estadual n. } 7.120 \text {, de } 13 \text { de } \\
\text { dezembro, foram concedidos foros de cidade à sede municipal e foi mudada a sua } \\
\text { denominação para Palmeiras (IBGE, } 1958, \mathrm{v} \text {. XXI). }\end{array}$} \\
\hline
\end{tabular}

Quadro 6: Ficha toponímica 3

Fonte: Elaborado pelos autores

\begin{tabular}{|c|c|}
\hline TOPÔNIMO & Antropotopônimo \\
\hline ACIDENTE & Humano/município \\
\hline $\begin{array}{c}\text { LOCALIZAÇÃO } \\
\text { GEOGRÁFICA }\end{array}$ & TI 03 \\
\hline ETIMOLOGIA & Portuguesa. Sobrenome port. de origem esp. (GUÉRIOS, 1981). \\
\hline $\begin{array}{c}\text { PERCURSO } \\
\text { ONOMÁSTICO }\end{array}$ & $\begin{array}{l}\text { Seabra < Dr. Seabra < Campestre < Vila Agrícola de Campestre < Campestre } \\
<\text { Passagem de Jacobina } \\
\text { Antropotopônimo<axiotopônimo<fitotopônimo<poliotopônimo<fitotopôn } \\
\text { imo<hodotopônimo }\end{array}$ \\
\hline $\begin{array}{c}\text { INFORMAÇÕES } \\
\text { ENCICLOPÉDICAS }\end{array}$ & $\begin{array}{l}\text { Em princípios do século XVII, florescendo as minas de ouro de Jacobina e de } \\
\text { Minas do Rio de Contas, a metrópole determinou a abertura de uma estrada } \\
\text { que ligasse os dois núcleos de exploração aurífera. Essa estrada atraiu os seus } \\
\text { primeiros povoadores que aí se fixaram. O local tornou-se ponto de pouso } \\
\text { para viajantes em trânsito para as minas. Formou-se ali a povoação } \\
\text { denominada Passagem de Jacobina. Nesta povoação, já com o nome de } \\
\text { Campestre, a capela construída anteriormente foi elevada à sede da freguesia } \\
\text { de Nossa Senhora da Conceição do Campestre, pela Lei provincial de } 15-03-\text { - } \\
\text { 1847. Posteriormente, pela Resolução provincial n. 1.014, de 08-05-1868, foi } \\
\text { a citada freguesia transferida para o município de Lençóis. O arraial de } \\
\text { Campestre foi elevado à categoria de vila, com a denominação de Vila } \\
\text { Agrícola de Campestre, pela Lei provincial n. } 2.652 \text {, de } 14-05-1889 \text {, que } \\
\text { também criou o município de Campestre, com território desmembrado do de } \\
\text { Lençóis. Pelo Decreto n. } 491 \text {, de } 27-06-1891 \text {, foi a vila elevada à categoria de } \\
\text { cidade, com o nome de Campestre. Pela Lei estadual n. } 1.126-A \text {, de } 27-08- \\
1915 \text {, o município teve sua denominação mudada para Dr. Seabra, em } \\
\text { homenagem ao então Governador do Estado, Doutor José Joaquim Seabra. } \\
\text { Pelos Decretos estaduais n. } 7.455 \text {, de } 23-06-1931 \text {, e n. } 7.479 \text {, de } 8 \text { de julho do } \\
\text { mesmo ano, o município e a cidade tiveram os nomes simplificados para } \\
\text { Seabra (IBGE, 1958, v. XXI). }\end{array}$ \\
\hline
\end{tabular}

Quadro 7: Ficha toponímica 4

Fonte: Elaborado pelos autores 
As fichas apresentadas nos revelam importantes fontes que contribuem para o conhecimento motivacional de denominação dos topos, bem como nos faz verificar o processo onomástico, sócio-histórico e cultural dos mesmos.

O modelo proposto por Dick e por nós elegido, constitui-se de 27 categorias taxionômicas. Dessas, localizamos apenas 9 no corpus de estudo, quais foram: Animotopônimos, antrotopônimos, cardinotopônimos, Ergotopônimos, fitotopônimos, geomorfotopônimos, hidrotopônimos, litotopônimos e zootopônimos, como visualizamos no gráfico a seguir:

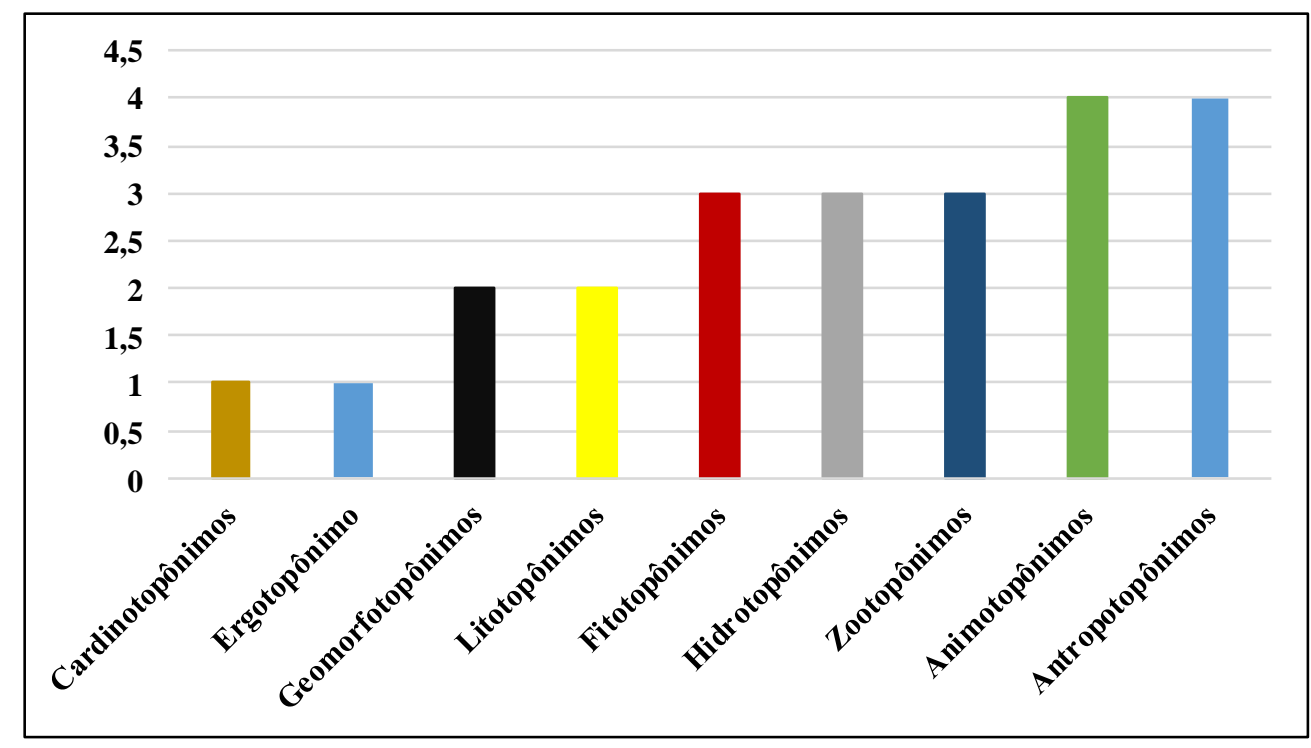

Gráfico 1: Divisão dos topônimos em taxionomias Fonte: Elaborado pelos autores, 2019

O gráfico 1 apresenta a distribuição dos topônimos por taxionomias, sendo mais produtivos aqueles referentes aos animotopônimos (4 ocorrências) e os antropotopônimos (4 ocorrências). Isso revela timidamente, que no processo de nomeação dos topos, a motivação se deu por aspectos relacionados a psique humana, religiosa e de representação de indivíduos marcados social e culturalmente.

Quanto à classificação toponímica, dos 23 topônimos analisados, 9 são de natureza antropocultural (39\%) e 14 de natureza física (61\%). Todavia, observemos o gráfico abaixo: 
RELACult - Revista Latino-Americana de Estudos em Cultura e Sociedade

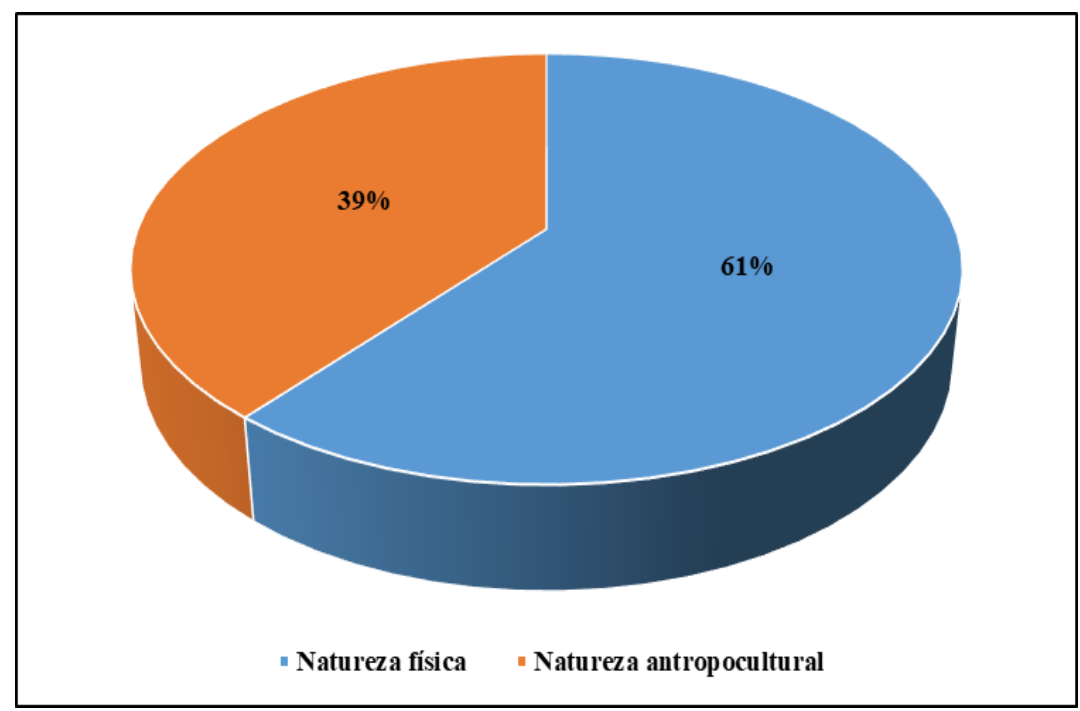

Gráfico 2: Divisão dos topônimos nas categorias quanto à sua natureza Fonte: Elaborado pelos autores, 2019

No gráfico 2, verificamos o quanto os aspectos ligados à natureza, à materialidade foram os principais motivadores para a denominação dos topos em estudo, demonstrando, dessa forma, como as motivações físicas marcam a memória do lugar, o que reafirma a ligação que o homem tem com o meio.

Em se tratando de natureza, física ou antropocultural, alguns elementos foram mais predominantes que outros.

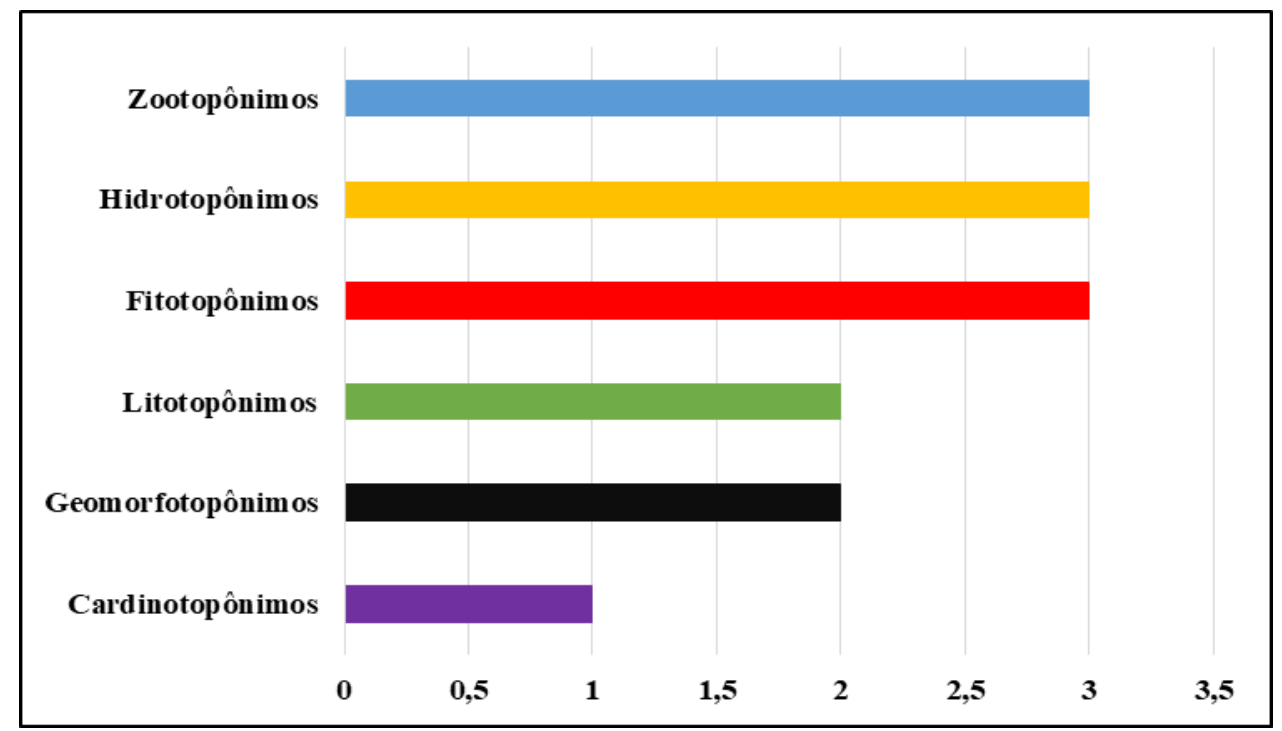

Gráfico 3: Divisão dos topônimos em taxionomias de natureza física Fonte: Elaborado pelos autores, 2019

O gráfico 3, apresenta uma predominância para elementos nativos no processo de nomeação dos topos, pois estes se relacionam diretamente com a fauna, flora, hidrografia, 
posições e formas geográficas que conduzem o lugar e que não passaram por despercebidos pelo homem.

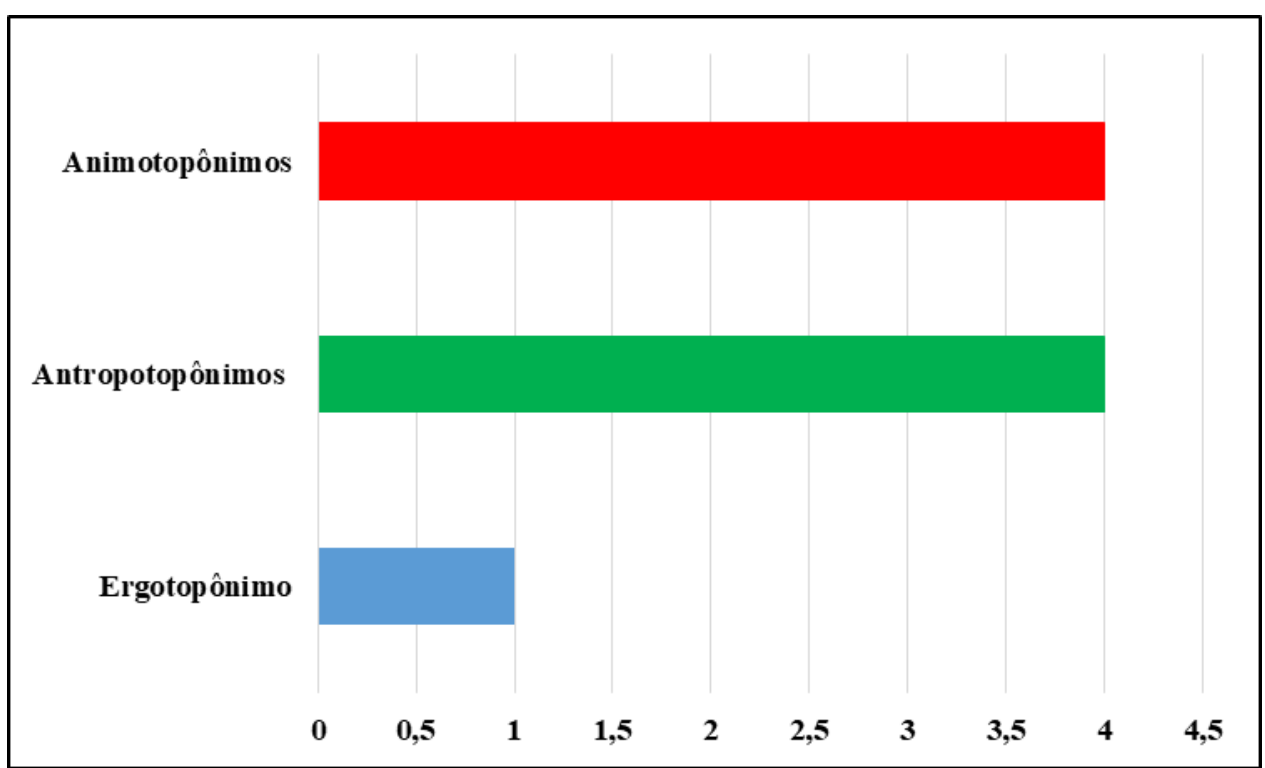

Gráfico 4: Divisão dos topônimos em taxionomias de natureza antropocultural Fonte: Elaborado pelos autores, 2019

No gráfico 4, podemos ressalvar a importância dos elementos de natureza antropocultural, menos produtivo que os de natureza física, porém não deixaram de ser utilizados no processo de nomeação do lugar, estes foram motivados pela psique vital e a cultura espiritual humana, bem como pelas representações humanas locais e a cultura material.

\subsection{Do plano morfo-estrutural}

Consideramos na análise a estrutura dos topônimos, classificando-os em simples ou compostos. Não levamos em consideração a categoria híbrido simples e híbrido composto, pois ambas categorias não foram encontradas. Observemos o gráfico: 


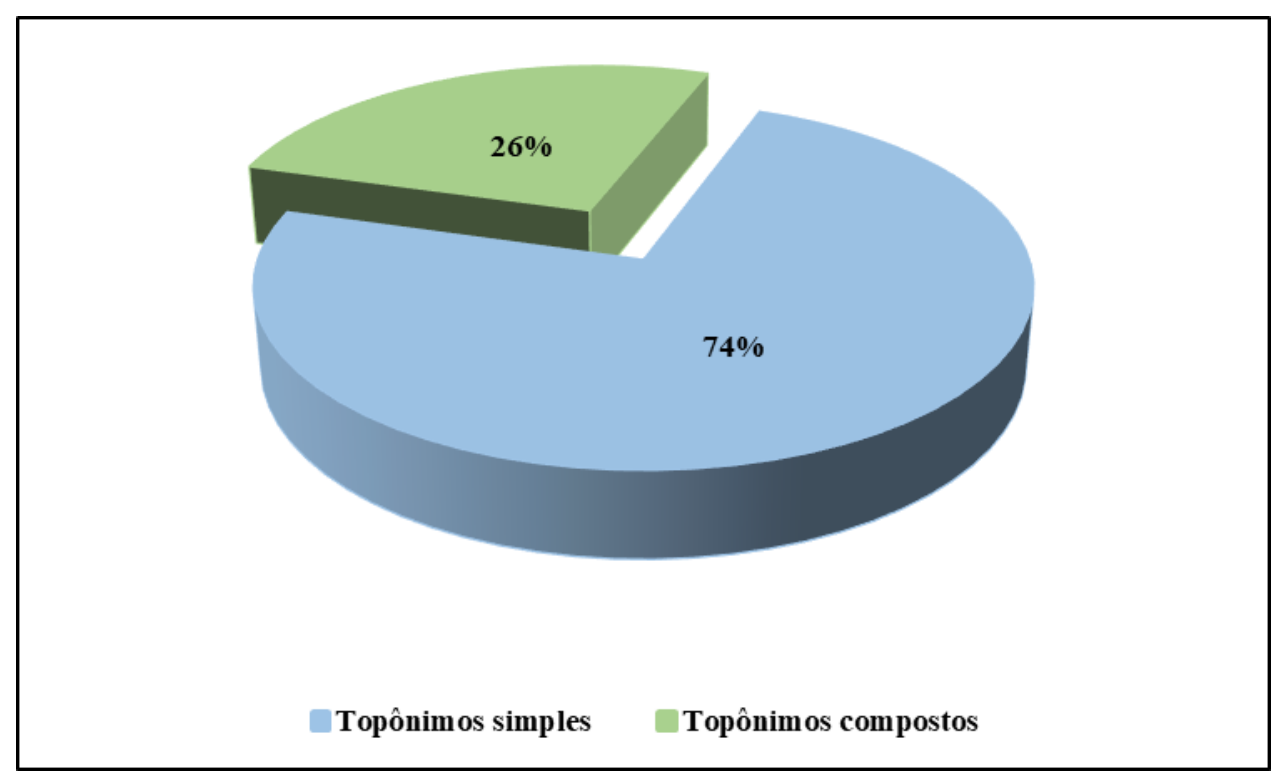

Gráfico 5: quantidade de topônimos em cada estrutura morfológica

Fonte: Elaborado pelos autores, 2019

Observamos no gráfico 5 a proporção das estruturas morfológicas dos topônimos do corpus. Dos 23 topônimos analisados, 17 são simples (74\%) e 6 são compostos (26\%).

Pouco pudemos explorar do plano morfo-estrutural, pois o dado não nos proporcionou outras informações, tais como elementos híbridos de uma mesma língua ou de línguas distintas. Mesmo assim, ficou patente que os nomes simples tiveram grande influência no processo nominativo, talvez pelo fato da simplificação linguística facilitar a fixação do mesmo, hipótese que pode ser melhor averiguada em trabalhos futuros.

\subsection{Do plano linguístico etimológico}

Observemos o gráfico abaixo. Ele apresenta a distribuição etimológica dos topônimos presentes no corpus de estudo: 


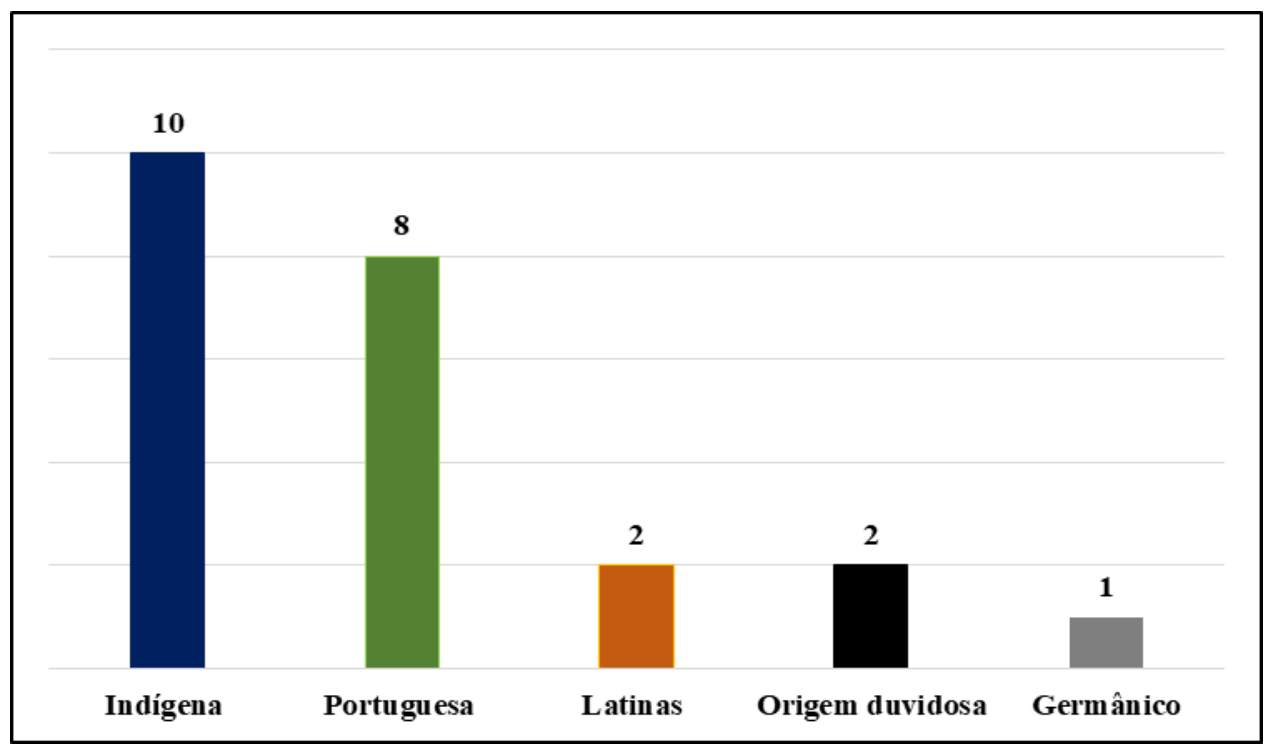

Gráfico 6: Frequência etimológica dos topônimos Fonte: Elaborado pelos autores, 2019

O gráfico 5 apresenta a etimologia dos topônimos, isto é, sua origem. Verificamos uma alta frequência para os topônimos de origem indígena (10), seguidos dos de portuguesa (08), latina (02), germânica (01) e origem duvidosa (02). A grande frequência de étimos indígenas pode ser explicado pelo processo de povoamento das microrregiões que têm em seu berço uma forte presença de índios.

\section{Algumas outras palavras, mas não finais}

Este estudo teve como finalidade apresentar e categorizar, os topônimos, de acordo com a metodologia de Dick (1980 [1990]) presentes no corpus que analisamos. Concretizamos isso através da análise toponímica e da classificação dos topos de natureza antropocultural e física.

A fim de tornar a análise substancial dividimo-la em três partes, apresentando o aspecto motivacional, a estrutura morfológica e etimológica dos topônimos.

Os resultados obtidos revelaram ser o signo toponímico um elemento valioso, capaz de recuperar fatos da memória de uma comunidade, bem como os valores sociais, históricos e culturais, através do estudo das designações nominativas.

Verificamos, também, que as taxes de natureza física foram mais recorrentes no processo de nomeação dos topos analisados, o que reflete a importância dos elementos da natureza, tais como: flora, fauna, geomorfologia, hidrografia). Tal riqueza se sobrepôs aos valores e manifestações do homem no processo de nomeação dos lugares. 
Quanto à etimologia, observamos que as taxes de origem indígenas, foram mais recorrentes e que, de tal modo, se relacionaram com a natureza física dos topônimos.

Não foi nossa intenção realizar uma análise exaustiva, mas sim apresentar de maneira sintética uma das maneiras de se trabalhar com os signos toponímicos. Assim, esperamos que a breve exposição possa ser alargada em trabalhos futuros por nós ou por outros pesquisadores.

\section{Referências}

BRASIL. Censo 2010. Disponível em: <http:// censo2010.ibge.gov.br/>. Acesso em: 20 mar. 2019.

BRASIL. Cidades. Disponível em: <http:// https://cidades.ibge.gov.br/>. Acesso em: 20 mar. 2019.

BRASIL. Território de identidade. Disponível em: <http:// http://www.sei.ba.gov.br/. Acesso em: 20 mar. 2019.

CRUZ, Myrt Thânia de Souza. A Chapada Diamantina e a convivência com o Semi-Árido: Ameaça de desarticulação e dissolução de comunidades locais. 2006. Tese (Doutorado) 190f. Pontifícia Universidade Católica de São Paulo (PUC/SP), São Paulo, 2006.

CUNHA, Antônio Geraldo da. Dicionário histórico das palavras portuguesas de origem tupi. São Paulo: Companhia Melhoramentos, Brasília: Universidade de Brasília, 1998.

. Dicionário etimológico da língua portuguesa. São Paulo: Nova Fronteira, 1986.

DICIONÁRIO ONLINE CALDAS AULETE. Disponível em: <www.aulete. com.br>. Acesso em: 20 mar. 2019.

DICK, Maria Vicentina de Paula do Amaral. Métodos e questões terminológicas na Onomástica. Estudo de caso: o Atlas Toponímico do Estado de São Paulo. Investigação Lingüística e Teoria Literária, v. 9. Recife: UFPE, 1999. p. 119-148.

Toponímia e Antroponímia no Brasil. Coletânea de estudos. São Paulo: Serviço de Artes Gráficas/FFLCH/USP, 1992.

Estado, 1990.

A motivação toponímica e a realidade brasileira. São Paulo: Edições Arquivo do

MAEDA, Raimunda Madalena Araujo. A Toponímia Sul-Mato-Grossense: Um Estudo dos Nomes de Fazendas, Araraquara. 284f. Dissertação de Mestrado - Faculdade de Ciências e Letras da Universidade Estadual Paulista, 2006.

ROLO, Maria do Carmo Sá Teles de Araujo. Apócope das vogais átonas [i] e [u] em duas localidades do Centro Sul Baiano: Beco e Seabra. 2010. 250f. Dissertação (Mestrado) - 
Universidade Federal da Bahia (UFBA), Programa de Pós-Graduação em Língua e Cultura, Salvador, 2010.

SALAZAR-QUIJADA, A. La toponímia em Venezuela. Caracas, Publicaciones de la Faculdad de Ciências Econômicas y Sociales, 1985. 178p. 